\title{
A INDÚSTRIA CULTURAL E O CONCEITO DE ALIENAÇÃO
}

\author{
THE CULTURE INDUSTRY AND THE ALIENATION CONCEPT
}

\author{
Stefane Katrini Koop ${ }^{1}$ \\ (stefanekoopk@gmail.com)
}

\begin{abstract}
RESUMO
O presente artigo visa abordar as consequências da Indústria Cultural nas produções estéticas e na forma de compreensão de mundo dos indivíduos, tendo como base as considerações de Theodor Adorno e Max Horkheimer apresentadas na obra Dialética do Esclarecimento (1944). Partindo do conceito de Indústria Cultural, os autores tratam de aspectos concernentes à vida humana, tendo em vista instrumentos de esclarecimento como o cinema, a música, etc. mostrando como ocorre o obscurecimento de uma autenticidade nesses âmbitos em prol do capital. Com base nisso, buscar-se-á expor, primeiramente, as consequências do mundo reificado na arte, elencando como isso se dá a partir da instauração da Razão Instrumental. Posteriormente, discutir-se-á como os produtos mercantis levam a anulação dos instrumentos de reflexão e na perda de subjetividade dos indivíduos, culminando na construção de uma sociedade formada de modo alienado e padronizado, tendo como objetivo ultrapassar um viés social da interferência desse sistema na concepção de arte, retomando uma reflexão filosófica acerca de como tal problemática afeta a forma com que os indivíduos se relacionam com o mundo.
\end{abstract}

Palavras-chave: Indústria Cultural. Alienação. Horkheimer. Adorno.

\begin{abstract}
The present article aims to address the consequences of the Cultural Industry in the aesthetic productions and in the way of understanding the world of the individuals, based on the considerations of Theodor Adorno and Max Horkheimer presented in the work Dialectic of Clarification (1944). Starting from the concept of Cultural Industry, the authors treat aspects related to human life, in view of enlightenment instruments such as cinema, music, etc. showing how the obscuration of authenticity in these areas in favor of capital occurs. Based on this, it will be tried to expose, firstly, the consequences of the reified world in the art, listing like this occurs from the instauration of the Instrumental Reason. Subsequently, it will be discussed how commercial products lead to the annulment of the instruments of reflection and the loss of subjectivity of individuals, culminating in the construction of a society formed in an alienated and standardized way, with the objective of overcoming a social bias of the interference of this system in the conception of art, returning to a philosophical reflection about how such a problem affects the way in which individuals relate to the world.
\end{abstract}

Key-words: Culture Industry. Alienation. Horkheimer. Adorno.

\footnotetext{
${ }^{1}$ Formada em Filosofia pela Universidade Estadual do Centro-Oeste (UNICENTRO) e pós-graduada em Gestão de Políticas Sociais pela Faculdade São Braz.

CV Lattes: http://lattes.cnpq.br/5619762202638203.
} 


\section{INTRODUÇÃ̃O}

A análise de como se apresenta a sociedade conforme seus períodos e de como os indivíduos se colocam diante das produções feitas nos âmbitos sociais são temas de reflexão ao longo da história da filosofia. A Escola de Frankfurt, criada em 1924, com sede no Instituto de Pesquisa Social - Institut für Sozialforschung -, marca, ao lado da hermenêutica, da fenomenologia e do neokantismo, um importante período da filosofia alemã no século XX. Surgida durante a República de Weimar, contava com membros que haviam presenciado a Primeira Guerra Mundial, a Revolução Russa e, sobretudo, a Segunda Guerra, fato que se reflete em suas produções. A Escola reuniu diversos filósofos e cientistas sociais de vertente marxista que elaboraram a chamada Teoria $\mathrm{Crítica}^{2}$, a qual buscava investigar as condições sociopolíticas e econômicas que incidiam na sociedade condicionada e padronizada da época.

Os frankfurtianos trataram de um leque de assuntos que compreendia desde os processos civilizadores modernos e o destino do ser humano na era da técnica até a política, a arte, a música, a literatura e a vida cotidiana. Dentro desses temas e de forma original é que vieram a descobrir a crescente importância dos fenômenos de mídia e da cultura de mercado na formação do modo de vida contemporâneo. (RÜDIGER, 2001, p. 132.)

A Teoria Crítica se contrapõe à Teoria Tradicional, dimanante da aurora da filosofia moderna, com René Descartes (1596 - 1650). Esta se fundamenta no método experimental e no cálculo matemático, correspondendo a um paradigma de racionalidade que se detém somente nos meios, negligenciando os fins e visando um ideal de neutralidade científica. As ciências naturais, meios da Teoria Tradicional, estão ligadas ao aparelho social com o fito de manter a reprodução e autopreservação do que já é existente. Tendo como exemplo a divisão social do trabalho, se consideram e se classificam os fatos em diretrizes conceituais, isto é, seus resultados "matemáticos", os quais não possuem nenhuma intenção de contestação da ordem vigente. $\mathrm{O}$ dominado aceita esta sua condição e, por conseguinte, aquele que domina acredita

\footnotetext{
2 O termo "Teoria Crítica" surge através do artigo publicado por Max Horkheimer, em 1937, intitulado "Teoria tradicional e teoria crítica" (Traditionelle und kritische Theorie). O texto foi escrito enquanto Horkheimer estava exilado nos Estados Unidos. Ele faz uso dessa expressão para fugir da terminologia "materialismo histórico" usada pelo marxismo ortodoxo hegemônico daquele período, ao qual por razões políticas e por querer mostrar que a teoria marxiana devia se importar em suas reflexões com outros aspectos críticos presentes na interpretação da realidade (o filosófico, o cultural, o político, o psicológico) criticava, buscando apontar que não se deveria deixar conduzir predominantemente por análises economicistas. Horkheimer ressignifica a teoria crítica como um desenvolvimento da crítica da economia política.
} 
em seu direito de ser dominador. Em contrapartida, a Teoria Crítica, por não desconsiderar os fins, aborda os dados da sensibilidade como ambivalentes, pois dizem respeito ao mundo material como apenas potencialmente humano, visto que ele é dominado pelo capital. É uma teoria voluntária e não neutra, já que a sobrecarga das forças reificadas ${ }^{3}$ descambam em injustiças que tornam impossível uma neutralidade teórica.

\begin{abstract}
A Teoria Crítica se apresenta, portanto, como um indispensável contraponto à Teoria Tradicional no que concerne à natureza da realidade externa, que é reconhecida de fato, mas não pode ser apreendida em sua totalidade; a epistemologia, que, ao buscar compreender a relação dialética entre o conhecedor e o cognoscível, aponta para a necessidade do primado do objeto; e a metodologia que, conduzida pelo objeto, aponta caminhos para o investigador refletir sua própria condição e proporciona elementos de crítica que permitam a superação da condição de dominação presente na ciência que é a dominação do homem pelo próprio homem - a partir de uma orientação material e histórica. (RAMOS, 2010, p. 5)
\end{abstract}

Uma das principais obras que tratam da Teoria Crítica é a Dialética do Esclarecimento dos filósofos e sociólogos alemães Theodor Ludwig Wiesengrund Adorno (1903-1969) e Marx Horkheimer (1895-1973), que foi escrita em 1944, publicada em 1949 e republicada em 1964. A obra apresenta uma crítica radical à sociedade contemporânea, sendo uma releitura filosófica do Iluminismo com base nas consequências extraídas desse período.

\title{
2. AUFKLÄRUNG COMO MISTIFICAÇÃO DAS MASSAS
}

No sentido mais amplo do progresso do pensamento, o esclarecimento tem perseguido sempre o objetivo de livrar os homens do medo e de investi-los na posição de senhores. Mas a terra totalmente esclarecida resplandece sob o signo de uma calamidade triunfal. O programa do esclarecimento era o desencantamento do mundo. (ADORNO/HORKHEIMER.2006, p. 16)

O iluminismo foi um movimento cultural da elite intelectual europeia do século XVIII, que teve como principal característica o enaltecimento da razão a fim de reformar a sociedade

\footnotetext{
${ }^{3}$ Reificar é dar novo significado ao objeto, o qual equivale-o em coisa. Passa-se a ignorar o processo ou significado para propósito de si. Tal conceito assemelha-se ao de fetichismo, mas na verdade, corresponde a sua contraparte. No capítulo I de O Capital, após Marx apresentar o fetichismo da mercadoria, afirma em seguida que a inversão que este produz faz com que as relações entre as pessoas e seus trabalhos se configurem como "relações reificadas entre as pessoas e relações sociais entre as coisas" (MARX, 1982, p. 71). I.e., se o fetichismo é um dar a vida autônoma às coisas, reificar é justamente o tratar enquanto coisa, subtrair a vida do que é propriamente humano.
} 
e o saber herdado da tradição medieval. Esse período gerou inúmeras produções nas diversas áreas do conhecimento, contribuindo no avanço da ciência e no próprio pensamento filosófico. Através dele se esperava um grande enriquecimento intelectual dos indivíduos, sendo o responsável por, de forma metafórica, iluminar e esclarecer os caminhos do conhecimento. $\mathrm{O}$ conceito Aufklärung, traduzido como Esclarecimento, tem seu exórdio com o filósofo alemão Immanuel Kant (1724 - 1804), que em um texto publicado acerca do tema, "O que é Esclarecimento?" (1784), o apresenta como a saída do homem de sua menoridade, homologada por ele mesmo. A menoridade é compreendida como sendo a incapacidade de se servir do próprio entendimento, dependendo da direção ou condução de outras pessoas ou instituições, como se caracterizava o conhecimento na Idade Média. Para Kant, o Esclarecimento expressa um meio pelo qual a emancipação intelectual dos indivíduos se torna possível, superando a partir dele a ignorância e a preguiça de se pensar por conta própria: "Sapere Aude! Tenha a coragem de fazer uso de seu próprio entendimento, este deve ser o lema do Esclarecimento" (A 488, Trad., p. 8).

Adorno e Horkheimer não desconsideram o potencial do Iluminismo e das suas contribuições para a sociedade, mas o problematizam sob uma nova perspectiva, considerando pontos que antes estavam obscurecidos pelas leituras positivas deste período. Assim, os filósofos referem-se ao Esclarecimento como sendo um desencantamento do mundo, uma desmistificação cética através de um processo de racionalização que engloba todos os setores da vida social do indivíduo, tendo início quando o espírito deixa de ser natureza externa, passando a ser também do corpo, da natureza interna do homem. O Esclarecimento é apontado como responsável pela repressão dos desejos dos indivíduos, fazendo com que cada vez mais contribuam com trabalho e esforço. O processo de racionalização da cultura Ocidental é visto como extremamente dominador, pois ao invés de imprimir uma vida digna aos seres humanos, acaba por instrumentalizar as próprias relações humanas.

O Iluminismo vende ao homem uma ideia de dominação e superioridade. O seu propósito inicial consistia em livrar o mundo dos mitos e da superstição, tirando o medo dos homens e os tornando senhores, porém, acabou aprisionando-os, colocando a razão como um instrumento e tornando descartável tudo o que não se adapta às medidas da calculabilidade e utilidade. Como consequência disso, o pensar acabou se coisificando, sendo substituído por algo automatizado e padronizado. Os trabalhadores passam a ter seus instintos negados, pois já não têm a opção de desfrutá-los conforme sua vontade - e, portanto, autonomia -, podendo apenas servir conforme espera o sistema: o indivíduo se afirma como instrumento dentro das instituições de poder que o Estado lhe apresenta. 
O pensar tem como faculdade subjetiva a razão, sendo esta a que julga, relaciona, compara e discerne os meios e os fins. Com o desenrolar da história, essa faculdade se tornou um instrumento compreendido como formal, ou seja, não é somente a faculdade interior do homem, mas é ela que personifica os objetos no mundo. O primeiro a tratar deste fenômeno foi Max Weber, em sua obra A Ética Protestante e o Espírito do Capitalismo (1905), em que definiu a racionalização como uma regularização humana na busca de determinados fins. Adorno e Horkheimer afirmam que a razão, além de ser um instrumento formal, se transformou em mera abstração, sendo em sua essência um mito: "O mito é esclarecimento, e o esclarecimento acaba por converter-se em mito" (ADORNO/HORKHEIMER, 2006, p. 28).

O esclarecimento consiste aí, sobretudo, no cálculo da eficácia e na técnica de produção e difusão. Em conformidade com seu verdadeiro conteúdo, a ideologia se esgota na idolatria daquilo que existe e do poder pelo qual a técnica é controlada. (A 488, Trad., p. 14)

O Esclarecimento acabou adquirindo um viés totalitário, sendo em si técnico, como um meio para obtenção de fins lucrativos. Visto isto, quando a razão dá mais importância para o domínio cognitivo da realidade, buscando propiciar a elaboração de tecnologias de controle dos processos naturais, tem-se a Razão Instrumental: nela o pensamento não possui mais preocupação pela finalidade com a qual é utilizado, se interessando somente pelos meios que o tornam capaz de gerar lucro. A racionalidade instrumental é estritamente formal, de modo que o conteúdo das ideias dessa racionalidade não é relevante, mas apenas a forma com que tais ideias e princípios podem ser utilizados, isto é, ela se caracteriza pela relação entre meios e fins. Segundo Adorno e Horkheimer: "A racionalidade técnica hoje é a racionalidade da própria dominação. Ela é o caráter compulsivo da sociedade alienada de si mesma” (A 488, Trad., p. 100).

\section{A INDÚSTRIA CULTURAL E SUA SIGNIFICAÇÃO}

A racionalidade da técnica pode ser compreendida como a racionalidade do próprio domínio, operando como instrumento que conduz à perda da autonomia dos indivíduos, continuamente imposta pelo sistema social em sua totalidade. Em função disso, eventos com cunho emancipatório passam a ser vistos como negócios, e seus fins comerciais são propiciados através da exploração descomedida de objetos culturais. O conceito de 
Indústria Cultural foi desenvolvido na obra Dialética do Esclarecimento para tratar das produções que tornam a cultura e a arte objetos mercantis, tendo o intuito de substituir a expressão "cultura de massa”, por esta gerar uma ambiguidade ao insinuar uma compreensão de cultura nascida prontamente nas camadas populares.

A Indústria Cultural traz como consequência a degradação da formação dos indivíduos em âmbitos culturais, culminando na ausência de autonomia dos mesmos. O indivíduo autônomo do Iluminismo torna-se apenas um anseio, pois a busca por produção e a conversão de tudo que existe em mercadoria se impôs no todo social, tornando o homem prisioneiro do capital. O progresso passa a anular o que se supõe ser o seu próprio objetivo: a ideia do homem (HORKHEIMER, 1976, p. 6).

Representa a etapa mais acabada da autodestruição do homem enquanto independente e o complemento necessário da racionalidade instrumental, que garante e perpetua o pleno funcionamento da sociedade administrada, encobrindo a anulação do sujeito perante os poderes econômicos, correspondendo a um sistema total, que abrange todos os aspectos da realidade. Tal Indústria é considerada consequência do capitalismo e do fetichismo, responsáveis por propagar um culto às mercadorias e ocultar dos seus produtos as características sociais do trabalho, tendo o objetivo de mascarar totalmente a relação social do trabalhador na produção das mercadorias, entre os trabalhos individuais e o trabalho total. Esse ocultamento da relação social na mercadoria torna seu valor de troca irreal, pois a quantidade de trabalho materializado no produto não é mais vista como valor humano, fazendo da relação coisa-e-homem uma relação de coisas. O próprio homem, enquanto indivíduo, é tratado como mercadoria, tendo a sua humanidade reduzida ao mundo dos objetos, enquanto aquele que produz e alimenta o sistema com seu labor.

Os produtos da Indústria Cultural não possuem autonomia e autenticidade, pois visam à produção em série e à homogeneização, de modo que a técnica passa a possuir um grande poder social, direcionado apenas aos economicamente mais fortes. Ao perseguir a integração vertical de seus consumidores, ela adapta seus produtos ao consumo das massas e em âmbitos gerais determina o próprio consumo, reduzindo a humanidade, como cada um de seus elementos, às condições que representam os seus próprios interesses. Desse modo, pode-se observar que a Indústria Cultural oferece aos indivíduos uma coisa e, ao mesmo tempo, priva-os dela.

[...] O princípio básico consiste em lhes apresentar tanto as necessidades, como tais, que podem ser satisfeitas pela indústria cultural, quanto em, por outro lado, antecipadamente, organizar essas necessidades de modo que o consumidor a elas se prenda 
sempre e tão só como eterno consumidor, como objeto da indústria cultural. (HORKHEIMER, 1976, p. 180)

Causando uma experiência de prazer aos que despendem seus feitos, esse sistema que lucra com a cultura e a arte tem como objetivo fazer com que os indivíduos vejam o mundo sempre da mesma forma e que ele sempre permaneça como é. Ela vende constantemente a imagem estereotipada do que é bom ou mau, agradável ou não, causando um adestramento nos que passam a colocar como verdade e a entender somente o que se encaixa no modelo já estabelecido nesses estereótipos. Adorno a considera um instrumento capaz de recalcar a imaginação, fazendo as pessoas terem prazer ao soterrar a capacidade imaginativa, que sempre envolve o prazer pelo esforço e pela atividade mental.

\section{ARTE ENQUANTO PASTICHE}

A cultura é uma mercadoria paradoxal. Ela está tão completamente submetida à lei da troca que não é mais trocada. Ela se confunde tão cegamente com o uso que não se pode mais usá-la. (ADORNO/HORKEIMER, 2006, p. 151)

O modo de entender a arte e o papel do artista variou através dos séculos. Nas sociedades ocidentais pré-capitalistas, a igreja ou os nobres financiavam o trabalho artístico, e, apesar de existirem artistas populares, neste período imperava a arte erudita. $\mathrm{Na}$ sociedade burguesa europeia, a arte ocupa um lugar importante na própria cultura e na civilização, sendo autônoma, dando ao artista liberdade para manifestar de modo existencial e social a sua criatividade. Isso dava à arte uma ideia de superioridade, colocando-a em um patamar que culminava com a elevação espiritual e cultural de quem tinha acesso a ela. Com o capitalismo e a tecnologia se expandindo, surgem nos meios de comunicação o rádio, e, posteriormente, a televisão e o cinema: a tecnologia dá a possibilidade de gravação sonora e com a imagética a reprodução e produção dos produtos artísticos, levando à comercialização e à divulgação destas baseadas em técnicas de persuasão manipuladoras, subversivas e subliminares.

A sociedade do consumo é caracterizada pela busca desesperada por satisfazer suas necessidades e desejos através da compra de bens de consumo material, colocados como uma tábua de salvação, responsáveis por resolver todos os problemas e levar por meio da compra ao bem-estar. Pode-se considerar que a cultura de modo geral é marcada, nos séculos XX e XXI, pelo consumo, fato decorrente da Revolução Industrial e da Revolução Tecnológica, que acarretaram a produção em série de fácil acesso em todas as áreas 
da sociedade. O consumismo se estendeu à arte e, como em todos os outros campos, tornou seu alcance universal. O Pop Art, por exemplo, foi um movimento artístico do pós-guerra, entre as décadas 50 e 60, que teve início na Inglaterra, mas ganhou força no EUA. O precursor do movimento em 1952 foi um grupo formado por jovens artistas e críticos, chamados Independent Group, que tinham como propósito desafiar ideias aceitas sobre a arte moderna e se utilizavam dos signos estéticos massificados como expressão artística, muitas vezes retirando materiais do contexto tradicional ao qual pertenciam, isolando-os ou juntando-os com outros produtos com fins contemplativos. Os artistas usavam a publicidade e as histórias em quadrinhos já existentes como recursos para sua produção, não se preocupando com o plágio, de modo que promoviam o próprio trabalho por meio de algo já conhecido, e ao mesmo tempo, davam visibilidade às marcas comerciais que representavam em suas obras, misturando arte e propaganda sem nenhum problema. A figura mais conhecida do Pop Art foi Andy Warhol (1928-1987). Em suas obras pode-se notar uma visão irônica da cultura de massa, e, além disso, uma apropriação do momento consumista e materialista em que estava inserido. Warhol buscava criar uma arte industrial, fazendo uso de meios e técnicas de produção em massa, mostrando isso claramente em obras como "Campbell'ssoupcans", "Green Coca-Cola Bottles" e "The Twenty-Five Marilyns" em 1962.

Em vista dessas criações em que "tudo vale", Adorno considera que os produtos da Indústria Cultural não podem ser considerados arte, mesmo sendo vendidos e propagados como tal, pois não possuem duas características essenciais: autonomia e autenticidade. Por terem como objetivo a execução em grande escala e a homogeneização, as técnicas de reprodução anulam a diferença existente entre o caráter da obra de arte em si e o sistema social, sendo uma produção estritamente mercantil. A relação entre a obra autêntica e o apreciador é ignorada, ao invés de requerer atenção, concentração, esforço e compreensão, seus produtos têm como característica a previsibilidade e a uniformidade, de modo que o consumidor não precisa utilizar suas faculdades mentais para absorvê-los. Na Indústria Cultural tudo é prescrito: o modo que o filme termina, como a canção de sucesso trata de seu tema etc.

Adorno propõe na Teoria Estética ${ }^{4}(1970)$, que apesar de inacabada é uma de suas principais obras, a noção de desartização (Entkunstung der Kunst), conceito que é entendido como um processo responsável por tirar da arte a sua especificidade, situada por ele como a perda da sua evidencia, forçando a ideia que é seu próprio conceito, a de que seja arte. A desartização é o reflexo da incompreensão dos indivíduos adestrados pela Indústria

\footnotetext{
${ }^{4}$ Usamos a edição portuguesa de 2008.
} 
Cultural, que leva ao não entendimento do que se vê e ao estreitamento das sensações estéticas propiciadas pelos sentidos. Esse não entendimento da obra é o estado cativo mantido pelos produtos mercantis, levando a dificuldade de mostrar a relevância da arte para os que estão imersos na cultura de massa, pois estes indivíduos já não possuem a ideia de uma expressão artística verdadeira, prevalecendo a desartização da arte em todos os campos em que ela se insere.

\begin{abstract}
Que as obras recusem a comunicação é uma condição necessária, mas de modo algum a condição necessária da sua essência antideológica. O critério central é a força da expressão, cuja tensão as obras falam com um gesto sem palavras. Desvelam-se na expressão como estigma social; a expressão é o fermento social da sua forma autônoma. A principal testemunha a este propósito seria o quadro de Picasso Guernica que por uma rigorosa incompatibilidade como o realismo prescrito, adquire justamente, graças a uma construção inumana aquela expressão que causa o seu caráter de protesto, para lá de todo o mal-entendido contemplativo. (ADORNO, 2008. p 358)
\end{abstract}

A causa da desartização é a própria sociedade administrada que se apresenta no capitalismo tardio, de modo que é na era da burguesia que ocorre a inexistência de substancialidade na arte por meio do movimento progressivo de emancipação, democratização e secularização. Visto isso, indo contra a ideia de Walter Benjamin, que considera possibilidades positivas da perda da aura e da reprodução, Adorno apresenta que o "alargamento das possibilidades revela-se em muitas dimensões como estreitamento" (ADORNO, 2008, p. 11). O filósofo considera que a reprodutibilidade técnica nada trouxe de positivo à arte, mas ao contrário, deu início ao seu esvaziamento e degeneração.

A combinação entre diversão e esclarecimento é considerada impossível, dado que a Indústria Cultural só responde pela função de entreter aquele que a consome, visando justamente a decadência dos seus sentidos, comprometendo a pretensão reflexionante da arte autêntica: “O espectador não deve ter necessidade de nenhum pensamento próprio, o produto prescreve toda reação. Toda ligação lógica que pressupunha um esforço intelectual é escrupulosamente evitada" (ADORNO/HORKHEIMER, 2006. p. 113). Adorno define a arte em consonância com a estética alemã de índole romântica, como sendo uma "antítese social da sociedade" (ADORNO, 2008, p. 19), pois despreza normas e preceitos de estrutura já preconcebidos, negando modelos éticos, políticos e religiosos que possam prescrever ou impor a sua forma.

A antiga afinidade de contemplador-contemplado é invertida. Ao reduzir a obra de arte a simples factum, gesto típico do 
comportamento de hoje, vende-se também em saldo o momento mimético, incompatível com toda a essência coisal. O consumidor pode à vontade projetar as suas emoções, os seus resquícios miméticos, no que lhe é apresentado. (ADORNO, 2008, p. 29)

É criada uma visão de realidade que oculta os efeitos do mundo massificado, e que se desdobra com o surgimento de um monopólio que se estende para a esfera social através dos meios de comunicação, responsáveis por legitimar e dar suporte a uma ética que atua como formação social, que ignora as produções autônomas e a alteridade das pessoas. A racionalidade técnica está na base da construção de um mundo simbólico-ideológico que se insere entre a subjetividade e sociabilidade, impossibilitando ao indivíduo toda experiência estética no mundo.

Considerando que as mudanças adotadas pelo mercado da cultura impossibilitam refletir acerca das questões pertinentes à arte, mostra-se essencial pensar acerca dos modos de mercancia dela através das formas de difusão de produtos culturais, buscando com isso entender os traços dialéticos da experiência estética dos indivíduos no mundo e de como estas vêm à luz enquanto propriedade subjetiva e autônoma. Assim, a problemática que permeia a arte atualmente leva a necessidade de um pensar crítico que seja mais acurado e que considere o conteúdo de verdade das obras como a sua verdade social, como imperativo de uma experiência estética que ultrapassa a aparência e que trate das experiências vividas e das expressões singulares. Na Teoria Estética, Adorno apresenta a noção de uma arte que não é comprometida com a racionalidade instrumental, distinta da arte tradicional: "Sua natureza é uma natureza que fala, que produz sentido histórico, que cria uma relação diferente, não instrumental, frente à sociedade" (TROMBETA, 1995, p. 78).

\begin{abstract}
A arte nega as determinações categorialmente impressas na empiria e, no entanto, encerra na sua própria substância um ente empírico. Embora se oponha à empiria através do momento da forma - e a mediação da forma e do conteúdo não deve conceber-se sem a sua distinção - importa, porém, em certa medida e geralmente, buscar a mediação no facto dessa forma estética ser conteúdo sedimentado. (ADORNO, 2008, p. 15)
\end{abstract}

O filósofo considera que a arte está diretamente ligada à imaginação, à sensibilidade $\mathrm{e}$ à inspiração do artista que a produz na busca do belo ou de qualquer outro sentimento, emoção e desejo, podendo gerar interpretações e críticas à realidade social. Se comparada com os objetos e práticas sociais, ela sempre gera interpretações críticas da realidade, pelo simples fato de não ser um desses objetos ou práticas. A beleza de uma obra de Beethoven é tão grande que necessariamente nos leva a ver a pobreza em que 
vivemos. O seu significado pode ser construído a partir dela própria, por meio da relação que se estabelece enquanto contemplativa, tornando-se social no momento em que adota uma visão antagônica e livre frente à sociedade administrada. Assim, a expressão crítica, política e a liberdade da arte frente ao que lhe é imposto pela razão instrumental é o que deve se fazer presente nas criações, apontando para um novo da arte que não sofre das imposições da produção capitalista. A arte moderna é considerada por Adorno como abstrata, isto é, direciona para o que não existe e que ainda não foi visto nem dito, não podendo ser modificado pela ideologia dominante. Segundo ele: "A identidade estética deve defender o não-idêntico que a compulsão à identidade oprime na realidade" (ADORNO, 2008, p. 23). É justamente a abstração característica da arte que encobre a razão esclarecedora e dominadora.

\section{ALIENAÇÃO E INDÚSTRIA CULTURAL}

O termo alienação é utilizado no senso comum para se abordar a compreensão imperfeita da realidade ou uma obliquidade perante a mesma. Com base nessa acepção, a alienação é analisada como algo subjetivo ou moral, que pode se configurar dependendo do esforço dos próprios indivíduos em relação a sua autonomia cultural ou ideológica. Distintamente dessa definição, para Karl Marx (1818 - 1883) o conceito de alienação (Entfremdung) refere-se a uma condição objetiva que é historicamente situada, sendo fruto do processo de divisão social do trabalho do sistema capitalista e da universalização da propriedade privada. Em sua obra Manuscritos Econômico-filosóficos (1932), Marx concebe o conceito de alienação como um processo que exterioriza a humanidade enquanto essência, refletindo no não reconhecimento desta ação. Isso se exprime quando o produto se torna independente e estranho ao sujeito que o criou: o processo final é visto unicamente enquanto resultado. Desse modo, pode-se dizer que o problema da alienação não é de cunho moral, mas ontológico, advindo de uma condição social historicamente situada, que faz com que a possibilidade de auto mediação, própria de cada sujeito, se volte contra eles mesmos.

Em primeiro lugar, o trabalho é exterior ao trabalhador, quer dizer, não pertence à sua natureza; portanto, ele não se afirma no trabalho, mas nega-se a si mesmo, não se sente bem, mas infeliz, não desenvolve livremente as energias físicas e mentais, mas esgota-se fisicamente e arruína o espírito. Por conseguinte, o trabalhador só se sente em si fora do trabalho, enquanto no trabalho se sente fora de si. Assim, o seu trabalho não é voluntário, mas imposto, é trabalho forçado. Não 
constitui a satisfação de uma necessidade, mas apenas um meio de satisfazer outras necessidades. O seu caráter estranho ressalta claramente do fato de se fugir do trabalho como da peste, logo que não exista nenhuma compulsão física ou de qualquer outro tipo. O trabalho externo, o trabalho em que o homem se aliena, é um trabalho de sacrifício de si mesmo, de mortificação. Finalmente, a exterioridade do trabalho para o trabalhador transparece no fato de que ele não é o seu trabalho, mas o de outro, no fato de que não lhe pertence, de que no trabalho ele não pertence a si mesmo, mas a outro. [...] Pertence a outro e é a perda de si mesmo. (ADORNO/HORKHEIMER, 2006, p. 162)

Marx apresenta uma tétrade desse problema, sendo o primeiro referente ao produto do trabalho, que corresponde à aversão entre indivíduo produtor e o produto. Neste caso, não ocorre o reconhecimento por parte do produtor e objeto criado; o produto torna-se independente, algo estranho à natureza do sujeito que o concedeu existência. Outro tipo de alienação é a alienação ativa, que ocorre no processo de produção. Ela trata da consciência de que o trabalhador se encontra alienado quanto ao produto de seu labor. Nesse caso, o trabalho corresponde a um tormento e não a uma realização, o que move a atividade dos trabalhadores não é o quanto precisam disso, mas as propensões dos que tem poder sobre eles. É nessa etapa que os indivíduos só têm satisfação em suas necessidades animais básicas: comer, dormir e beber. Os trabalhadores são levados a uma rotina em que o sentimento de insatisfação sobre a própria vida e a negação de atividades propriamente humanas são entendidas como normais. $\mathrm{O}$ trabalho lhes é algo aquém, incomum, além disso, são empregados somente por coerção, trabalhando sempre para alguém ou por alguém. Outro modo de alienação pontuado por Marx é a que corresponde à anulação do entendimento de humano enquanto um ser multifacetado, possuidor de inúmeras capacidades e potencialidades, tornando-o apenas um indivíduo solitário quando separado da sua essência e do vínculo com a comunidade. O trabalho é um fator individualizante que reflete na transformação do sujeito, que deixa de ser multifacetado e se configura enquanto unilateral, ipso facto, a sua existência não vale enquanto ser humano e parte de um gênero, mas como trabalhador, único, permeando apenas a esfera da individualidade. $\mathrm{O}$ último modo de alienação é em relação aos outros homens, sendo um desdobramento da individualização. Ao passo que não há o reconhecimento no trabalho, vendido pelo sistema como aspecto mais fundamental da vida, a sua vida se torna sem significado.

Semelhante fato implica apenas que o objeto produzido pelo trabalho, o seu produto, se lhe opõe como ser estranho, como um poder independente do produtor. $\mathrm{O}$ produto do trabalho é o trabalho que se fixou num objeto, que se transformou em coisa física, é a objetivação do trabalho. A realização do trabalho constitui simultaneamente a sua objetivação. A realização do trabalho aparece na esfera da economia política como desrealização do trabalhador, a 
objetivação como perda e servidão do objeto, a apropriação como alienação. (ADORNO/HORKHEIMER, 2006, p. 159)

O sistema capitalista gera necessidades no sujeito e a jornada de trabalho é sempre um motivo de esgotamento físico, mental e emocional. Para que seja possível exercer todas as funções que o sistema espera, muitos dos desejos devem ser desconsiderados ou ignorados, de modo que, por mais que haja um sentimento de realização através do dinheiro e do status, a satisfação em si mesma é constantemente minada. "Os próprios seres humanos se tornaram parte desse mundo retificado, e sua subordinação à lógica da dominação é realçada pela mercantilização da força de trabalho dentro do capitalismo" (THOMPSON, 1995, p. 131). A eficácia da ideologia da sociedade capitalista está na capacidade que ela possui de vedar o acesso aos resultados da atividade social como produtos, mediante o bloqueio da reflexão sobre o modo como estes produtos foram produzidos.

Na medida em que nesse processo a indústria cultural inegavelmente especula sobre o estado de consciência e inconsciência de milhões de pessoas às quais ela se dirige, as massas não são, então, o fator primeiro, mas um elemento secundário, um elemento de cálculo; acessório da maquinaria. O consumidor não é rei, como a indústria cultural gostaria de fazer crer, ele não é o sujeito dessa indústria, mas seu objeto. (...) A indústria cultural abusa da consideração com relação às massas para reiterar, firmar e reforçar a mentalidade destas que ela toma como dada a priori e imutável. É excluído tudo pelo que essa atitude poderia ser transformada. As massas não são a medida, mas a ideologia da indústria cultural, ainda que esta última não possa existir sem a elas se adaptar. (ADORNO, 1996, p. 288)

A ideologia que a Indústria Cultural impõe apresenta os dados da experiência social como sendo imediatos, não havendo uma mediação pelo processo que o tornou possível. Os homens renovam com seu próprio trabalho uma realidade que os escraviza e em medida crescente os ameaça com todo tipo de miséria. Adorno afirma que a cultura de massa ${ }^{5}$ é por um todo narcisista, pois vende a satisfação manipulada, tornando o próprio divertimento um meio para que os indivíduos se sintam representados (nas telas do cinema e da televisão, nas músicas e nos vários espetáculos) e não se vejam como meros consumidores alienados. Por conseguinte, os indivíduos do capitalismo contemporâneo precisam, como Narciso, de um espelho em que possam recobrar o amor e o reconhecimento por sua própria imagem, tão comprometidos pelo

\footnotetext{
${ }^{5}$ Corresponde ao conceito de cultura toda ação humana sobre o contexto natural e social e o resultado dessa ação, configurando- se em fenômenos sociais, políticos, econômicos, religiosos, artísticos, bem como na expressão de um conjunto de valores, sendo possível sua representação pela obra de arte." IOP, Elizandra. Formação Cultural, semi-cultura e a indústria cultural: contribuições de Adorno sobre a emancipação. (REP. 2009, p. 22)
} 
esforço desgastante de continuar a gerar valores financeiros. Assim, como o sistema visa apenas a comercialização e o lucro, as mercadorias culturais passam a ser objeto de valor, o que passa a interferir na sua criação e no conteúdo produzido. A mercantilização da cultura tende a criar um conformismo e o gosto domesticado que almejam a integração das massas ao próprio sistema.

Divertir-se significa estar de acordo. A diversão é possível apenas enquanto se isola e se afasta a totalidade do processo social, enquanto se renuncia absurdamente desde o início à pretensão inelutável de toda obra, mesmo da mais insignificante: a de, em sua limitação, refletir o todo. Divertir-se significa que não devemos pensar, que devemos esquecer a dor, mesmo onde ela se mostra. É, de fato, fuga, mas não, como pretende, fuga da realidade perversa, mas sim do último grão de resistência que a realidade ainda pode ter deixado. A libertação prometida pelo entretenimento é a do pensamento como negação. A impudência da pergunta retórica: "Que é que a gente quer?" consiste em se dirigir às pessoas fingindo tratá-las como sujeitos pensantes, quando seu fito, na verdade, é o de desabituá-las ao contato com a subjetividade. (ADORNO/HORKHEIMER. 2006, p. 119.)

Nesse sentido, a cultura industrializada propagaria a aceitação de uma vida desumana proporcionada pelo capitalismo, diante da qual o indivíduo não tem saída, senão se entregar. O seu efeito seria, como já foi dito, uma mistificação, uma maneira de impedir a consciência das massas, não permitindo a formação de uma sociedade autônoma e capaz de efetivar a ideia iluminista de sapere aude. A ideologia da Indústria Cultural tem a função de aprofundar mais ainda a condição de alienação social, mantendo assim um sistema que se alimenta dos indivíduos. 


\section{REFERÊNCIAS}

ADORNO, Theodor W. Teoria Estética. Lisboa: Edições 70, 1970.

ADORNO, Theodor W. (et al.). Teoria da Cultura de Massa. Introdução, Comentários e Seleção de Luiz Costa Lima. Rio de Janeiro: Paz e Terra, 1986.

ADORNO, Theodor W. Teoria da semicultura. Educação e Sociedade. 1996. . Educação e emancipação. 2. ed. Rio de Janeiro: Paz e Terra, 2000.

ADORNO, Theodor W.; HORKHEIMER, Max. Dialética do Esclarecimento. Tradução de Guido Antonio de Almeida. Rio de Janeiro: Jorge Zahar Editor, 2006

ARISTÓTELES. Poética. São Paulo: Nova Cultural, 1999. (Coleção Os Pensadores)

BENJAMIN, Walter. Magia e técnica, arte e política. Tradução de Sérgio Paulo Rouanet. São Paulo: Brasiliense, 1985.

DUARTE, Rodrigo A. de Paiva. Mímeses e Racionalidade. São Paulo: Loyola, 1993. "O esquematismo kantiano e a crítica à indústria cultural". In: Revista Studia Kantiana, Campinas, n. 4 (1): 2003b. p. 85-105.

FREITAS, Verlaine. Adorno e a Arte Contemporânea. Rio de Janeiro: Jorge Zahar Editor, 2003.

HARRINGTON, Michael. O Crepúsculo do Capitalismo. Rio de Janeiro, Civilização Brasileira, 1977.

HORKHEIMER, Max. Teoria Tradicional e Teoria Crítica. In: Coleção Os Pensadores. São Paulo: Editora Abril, 1975.

KANT, Immanuel. Crítica da faculdade do juízo. Tradução de Valerio Rohden e Antonio Marques. Rio de Janeiro: Forense Universitária, 1993.

Crítica da razão pura. Tradução de Valerio Rohden e Udo B. Moosburger.

4 a ed. São Paulo: Nova Cultural, 1991. (Coleção Os Pensadores) . "Resposta à pergunta: O que é 'Esclarecimento’? In: Textos Seletos. Petropólis: Vozes, 1974. p. 100-117.

LOPARIC, Zeljko. A semântica transcendental de Kant. Campinas: Centro de Lógica, Epistemologia e História da Ciência da UNICAMP, 2002. 123

MARQUES, Ubirajara Rancan. "Notas sobre o esquematismo na Crítica da Razão Pura de Kant”. In: Revista Trans/Form/Ação. São Paulo, n. 18, 1995, p. 121-140.

MARX, Karl. Manuscritos Econômicos-Filosóficos. In: FROMM, Erich. Conceito Marxista do Homem. $8^{\mathrm{a}}$ edição, Rio de Janeiro, Zahar, 1983. 
MARX, Karl. O Capital. Vol. 2. $3^{\text {a }}$ edição, São Paulo, Nova Cultural, 1988.

RABAÇA, Silvio Roberto. Variantes Críticas: a Dialética do Esclarecimento e o Legado da Escola de Frankfurt. São Paulo: Annablume, 2004.

RAMOS, Carlos. Breve ensaio acerca das principais diferenças entre a teoria tradicional e a teoria crítica. USP. 2010.

RÜDIGER, F. Comunicação e indústria cultural: a fortuna da teoria crítica nos estudos de mídia brasileiros. Revista Brasileira de Ciências da Comunicação. 1998

RÜDIGER, Francisco. Comunicação e Teoria Crítica da Sociedade: Adorno e a Escola de Frankfurt. Porto Alegre: EDIPUCRS, 1999.

F. Comunicação e teoria crítica da sociedade: Adorno e a Escola de Frankfurt. Porto Alegre, Edipucrs. 1999

. F. A Escola de Frankfurt. In: V.V. 2001. FRANÇA; A. HOHFELDT; L.C. MARTINO (org.). Teorias da comunicação: conceitos, escolas e tendências. Petrópolis, Vozes, p. 131-150.

THOMPSON, John. Ideologia e Cultura Moderna: Teoria Social Crítica na Área dos Meios de Comunicação de Massa. Petrópolis: Vozes, 1995.

TROMBETA, Gerson Luís. A Racionalidade Artística como Contraponto À Racionalidade Instrumental. Revista Filosofia e Ciências Humanas. Passo Fundo, Ano 11, No. 01, Janeiro/Julho de 1995, p. 77-89. 